\title{
Leer una serie y ver una novela: sobre las funciones de la ficción literaria en Los muertos de Jorge Carrión
}

yarcelo Topuzian / Universidad de Buenos Aires - CONicet / mtopuzian@gmail.com

\section{Resumen}

La consideración de las relaciones entre novela y ficción televisiva por parte de los estudios literarios suele moverse entre dos extremos, que suponen también dos actitudes lectoras e, incluso, dos morales de la disciplina: las caracterizaciones de los efectos - generalmente objeto de valoración negativa- de la segunda sobre la narración y la escritura literarias actuales en general y el análisis de procedimientos específicos a través de los cuales la primera acusaría recibo de esos efectos sin mayor consideración valorativa. Por otro lado, desde los estudios audiovisuales y de los medios se ha llamado la atención sobre las diferentes implicaciones de lo que podría caracterizarse como una creciente «literarización» de estos productos televisivos que, por supuesto, implica atender a rasgos de la literatura que exceden su configuración meramente escrituraria y textual. Jorge Carrión se ha ocupado de este problema, evitando estratégicamente posicionarse de manera absoluta en uno u otro de estos puntos de vista, tanto a través de sus ensayos, como de su novela Los muertos; a esta última se referirá este trabajo. En ella, la configuración estructural del texto repone la problemática presentada y los puntos de vista mencionados, y a partir de ello explora concreta y prácticamente las opciones que se le ofrecen a la novela en la contemporaneidad. De este modo, Carrión invoca los circuitos y estrategias de valoración y legitimación subyacentes en el cruce problemático entre literatura canónica y producción mediática, y sobre la base de una narración novelesca diseña una reflexión sobre las condiciones de un pensamiento de la transición como figura de una historización posible de este cruce.

Palabras clave: televisión • literatura • ficción • valor

\section{Abstract}

The study of the relationship between novel and TV fiction by literary studies often moves between two extremes, which also involve two reading attitudes and even two moralities of the discipline: an indication of the effects -often negatively valued- of TV fiction over contemporary literary narration and writing and the analysis of specific procedures through which literature would receive these effects, without further evaluative consideration. On the other hand, media studies have drawn attention to the different implications of what could be characterized as a growing «literarization» of the TV products; this implies addressing traits of literature that exceed its purely scriptural and textual 
configuration. Jorge Carrión has addressed this problem by avoiding strategically either of these absolute views, both through his essays and his novel Los muertos; this paper is about the latter. In Los muertos, the structural configuration of the text replaces the problems presented and the views above mentioned; it explores concrete and practically the options that are offered in contemporary times to the novel as genre.
Thus, Carrión invokes the assessment and legitimation circuits and strategies underlying the troubled crossing between canonical literature and media production, and designs a reflection, based on a fictional narrative, on the conditions of a thought of the transition as a figure of a possible historicization of this crossing.

Key words: television $\cdot$ literature $\cdot$ fiction $\cdot$ value
Más allá de que la televisión se haya constituido, desde hace tiempo y con pleno derecho, como objeto de estudio e investigación en el campo de las humanidades, atrayendo operaciones, actitudes y valoraciones diferentes entre sí y que de ningún modo se dejan reducir ya a opciones maniqueas como la de "apocalípticos e integrados» o sus diversas herederas - al tiempo que, a este propósito, términos abarcadores como «cultura de masas» o «medios de comunicación» (de los que también se servía Eco) se han vuelto crecientemente obsoletos para abarcar fenómenos tan disímiles como, por ejemplo, las redes informáticas, las cadenas informativas internacionales y los videojuegos, incluso a pesar de lo que se ha caracterizado como su "convergencia» (Jenkins)—, también es cierto que, en tanto conjunto de disciplinas académicas, las humanidades siguen sirviéndose, de manera más o menos inercial, de sus viejos paradigmas para la constitución de objetos de estudio y proyectos de investigación sin tener del todo en cuenta los posibles efectos sobre esos paradigmas y focos de interés a que da lugar la creciente imbricación de sus viejos "cotos de caza» — por ejemplo, y para simplificar, el mundo de las letras - con su «terra incognita» de hoy — por ejemplo, las series de televisión-. Esto hace que, hacia el interior del campo, y sobre todo en el plano de las motivaciones y los hábitos no siempre explícitos y reflexivos de sus actores, muchas de aquellas viejas nociones sigan resultando operativas, aunque sea como recurso argumentativo abreviado o simple prejuicio implícito. Y que, al mismo tiempo - y ya no sólo hacia el interior- comience a asentarse la conciencia de algo que no puede percibirse sino como una creciente «literarización» de algunos productos televisivos, lo cual implica, desde ya, tener que empezar a prestar atención a aquellos rasgos de la literatura que pueden exceder — hoy y ayer- su configuración meramente escrituraria y textual, todavía presupuesta por aquel paradigma inercial al que nos referíamos.

Jorge Carrión se ha ocupado de este conjunto de problemas tanto a través de sus ensayos críticos Telefreud y, sobre todo, Teleshakespeare, como de su novela Los muertos; a esta última se referirá centralmente este trabajo. En ella —según nuestra hipótesis-, la configuración estructural del texto repone la problemática presentada y los puntos de vista mencionados, y a partir de ello explora concreta y
Fecha de recepción: 24/IO/20I4

Fecha de aceptación: $\mathrm{I} 2 / \mathrm{I} 2 / 2 \mathrm{OI} 4$ 